Estudos RBEP

\title{
Pedagogia como ciência da educação: retomando uma discussão necessária*
}

Liliana Soares Ferreira

\section{Resumo}

Sistematiza estudos que vêm sendo realizados no sentido de elaborar argumentos que re-afirmem a Pedagogia como ciência da educação, uma ciência dialogicamente elaborada, capaz de compreender sujeitos e ações, considerando a linguagem, a subjetividade e a historicidade também implicadas nos fenômenos. A pesquisa bibliográfica foi realizada com vista a levantar dados sobre o tema. Procedeu-se à categorização mediante a leitura dos sentidos mais evidenciados pelos autores lidos. Apresenta as sistematizações sobre a historicidade da Pedagogia, a discussão sobre ciências da educação e reflexões sobre o trabalho dos pedagogos. Esta discussão é inicial e exige, cotidianamente, ser assumida pelos sujeitos da educação. Deste modo, poder-se-á contribuir para a recuperação, ao lado do lugar social da educação, também do reconhecimento dos pedagogos, e mais, da educação como preponderante para a tão necessária transformação social.

Palavras-chave: Pedagogia; ciência; trabalho; escola.

* Artigo escrito com base em projeto desenvolvido com apoio do Conselho Nacional de Desenvolvimento Científico e Tecnológico (CNPq). 


\section{Abstract \\ Pedagogy as the science of education: resuming a necessary discussion}

This article surveys studies that have been carried out with the aim of presenting arguments that reassert Pedagogy as the science of education, a dialogically constructed science, that is able to understand subjects and actions, considering language, subjectivity and historicity involved in phenomena. Aiming to collect data about this subject, a bibliographical survey was done. The categorization was defined according to the senses that are more emphasized by the authors. Afterwards, a systematization of the historicity of Pedagogy, a discussion about education sciences, and some thoughts about the work of pedagogues are presented. This discussion is still initial and needs to be permanently considered by those involved in education. By doing this, they will contribute to resume the social recognition of pedagogues as well as that of the prevalent role of education in the so necessary social transformation.

Keywords: Pedagogy; science; work; school.

\section{Introdução}

A compreensão da Pedagogia atual implica a recuperação de um passado que a constituiu. Ao recuperá-lo, está-se buscando re-encontrar os aspectos que possibilitam a compreensão da Pedagogia como ciência da educação. Utilizo "ciência" no singular porque creio ser ela única, embora em integração contínua com outras ciências. Neste sentido, a pluralização, a meu ver, a desfoca e desqualifica. Ainda que alguns autores sejam incisivos ao proporem essa pluralização, penso que pluralizar pode reforçar uma incompreensão da Pedagogia como ciência da educação, na medida em que isto contribui para, semanticamente, no início, generalizar e, na prática, mais tarde, incitar novamente a pensar que ela é genérica, sem especificidades de estudo, por isto, uma área do conhecimento menor e, como tal, não tratada como ciência. Mas é uma ciência, como afirma Genovesi (1999, p. 79-80), autônoma, com uma linguagem que lhe é peculiar, utilizada com modos próprios e adequados a fins específicos, o que produz "[...] um corpo de conhecimentos, uma série de experimentações e de técnicas sem o que lhe seria impossível qualquer construção de modelos educativos".

Quando reitero ser a Pedagogia a ciência da educação, não estou a defender uma cientificidade unitária, tampouco uma ciência pautada por 
verdades e ortodoxias. Defendo uma ciência dialogicamente elaborada, capaz de compreender sujeitos e ações, com um rigor marcado pela cientificidade, com certeza, mas considerando a linguagem, a subjetividade e a historicidade também implicadas nos fenômenos. É por motivos dessa ordem que discordo de afirmações como:

A passagem do singular ao plural, da pedagogia definida como "a ciência" da educação à denominação de "ciências" da educação, revela, entretanto, uma transformação que não é sem importância e que marca o esquecimento progressivo da intenção original da pedagogia (isto é, melhoria do ensino nas salas de aula) e a emergência de inúmeras disciplinas contributivas, que trabalham menos diretamente para o progresso do ensino do que na produção e na acumulação dos conhecimentos a partir das problemáticas desenvolvidas em seu campo disciplinar respectivas. (Gauthier et al., 1998, p. 330).

Embora se conheçam trabalhos de Gauthier que abordam uma sequência de tempos de elaboração da Pedagogia, não se fará menção a eles, considerando-se não haver concordância com a defesa que o autor e seu grupo de trabalho fazem de um pedagogo-prático ou de uma reflexão prática. Estes argumentos do autor e de seu grupo de estudo, a meu ver, acabam por gerar incompreensões assentadas na prática pela prática, distanciando a Pedagogia daquilo que a constitui como ciência: a teorização da educação, com e a partir do trabalho dos professores e dos pedagogos, nos cotidianos da escola. Afirmações assim produzem, sublinearmente, confusões entre a Pedagogia e as áreas que a integram, quais sejam, a Didática e a Metodologia. Especialmente em relação à Didática, há muitas referências de ser sinônimo de Pedagogia. Neste sentido, aprecio a argumentação de Franco (2008, p. 361):

Sabe-se que à medida que a Pedagogia foi (ou é) considerada como tecnologia ela só pode produzir conhecimentos referentes à técnica; se a Pedagogia é considerada em seu viés metodológico, ela produzirá conhecimentos sobre métodos; se, por outro lado, a Pedagogia é concebida como ciência da e para a práxis educativa, ela poderá produzir conhecimentos que fundamentam tal prática, delineados a partir dos saberes pedagógicos, construídos pelos docentes. É nessa terceira perspectiva que se afirma a necessária indissociabilidade entre Didática e Pedagogia.

Por isso, um outro aspecto fundamental para discutir-se a ciência da educação está em considerar que Pedagogia, metodologia e didática são diferentes. De modo objetivo e breve, explico meu entendimento: Pedagogia é a ciência; metodologia é uma escolha cotidiana feita por quem pensa um ato pedagógico; e didática é a ação pedagógica em si, seu modus operandi e as concepções que o subsidiam. Isto posto, percebe-se que didática e metodologia são integrantes da Pedagogia, e esta é responsável por pensar e propor didáticas e metodologias em acordo com as teorias e entendimentos da educação. Neste sentido, vale o alerta de Pimenta (1999, p. 9): a Pedagogia é uma ciência que "[...] tem como objeto de estudo a educação. Como fenômeno social, a educação não se esgota 
no estudo de uma única ciência. Como fenômeno múltiplo, é síntese de múltiplas determinações". Tal entendimento, segundo a autora, exige uma ciência com

[...] pluralidade de enfoques sobre si. Enfoques que, para além dos discursos produzidos sobre o real, a ele se voltam permanentemente com a indagação a respeito de seu potencial e seus limites para compreendê-lo. E, consequentemente, a partir das novas demandas da realidade, rever a si mesmos. (Pimenta, 1999, p. 9).

Quanto ao objeto de estudo central, a Pedagogia tem a educação, esse fenômeno humano, portanto social, político, cultural, epistemológico, antropológico, filosófico, psicológico, enfim, um fenômeno que, para ser estudado, exige esforços conjugados de ciências diferentes associadas à Pedagogia. O fenômeno é do âmbito da Pedagogia; os estudos, os aportes teórico-metodológicos selecionados para estudá-lo podem incluir outras ciências, mas convocadas a partir da perspectiva da Pedagogia. É essa a compreensão a ser resgatada, no meu entender. Isto tudo porque, segundo Marques (1990, p. 24), a Pedagogia "[...] não pode se limitar ao entendimento de como se dão as relações educativas de fato e ao estabelecimento de diretrizes gerais para a educação nos horizontes ampliados da emancipação humana e da maioridade dos sujeitos". A esta ciência, cabe

[...] presidir a organização e condução da instituição educativa, no sentido de como se vão dar as relações internas do poder, mediadas pela infraestrutura de recursos e controles e de como se vão relacionar a gestão institucional, a dinâmica das relações interpessoais e a produção circulação dos conhecimentos. (Marques, 1990, p. 24).

Do mesmo modo, penso ser significativo destacar que não há Pedagogia somente na escola, mas em todo o contexto social. Considero também possibilidades mediadas pelas tecnologias, gerando ações pedagógicas em muitos outros espaços sociais ampliados. Ou seja, a Pedagogia é elemento cultural no sentido amplo, integra a cultura e é dela referente, além de contribuir para sua socialização. Portanto, pode-se compreender que "[...] o educativo (e o escolar) fazem parte de uma complexa engrenagem cultural e social" (Solà, 1995, p. 215-216) .

Em um contexto social cujos meios de comunicação, de modo geral, destacam estar ocorrendo uma crise da educação e da escola e a justificam ressaltando as condições precárias em que se encontram as escolas, revelando os salários precários que recebem os professores, quando noticiam sobre os baixos índices nas avaliações realizadas com base na ação regulatória do Estado, preocupa-me demasiadamente o descaso com que vem sendo tratada a educação e, em decorrência, todos os elementos atinentes à escola, ao conhecimento, ao currículo, às políticas públicas educacionais, à gestão da educação e, sobretudo, à Pedagogia, que entendo como ciência da educação e a favor da qual tenho empreendido esforços de estudo no sentido de buscar elementos que auxiliem na sua re-afirmação como ciência. Assim agindo, penso estar também, de alguma forma, 
procurando elementos para reconstituir a imagem social dos pedagogos, também desgastada, quando, no entanto, seriam os sujeitos fundamentais na elaboração e proposição de alternativas para a retomada de um processo educacional em acordo com as demandas contemporâneas.

Neste processo, estou re-encontrando autores e textos que me auxiliam a confirmar que não estou equivocada em entender que há sim uma ciência, cujo objeto é a educação, com todas as interfaces necessárias com outras ciências. Este texto é a sistematização dos estudos até a presente fase.

Essa preocupação em esclarecer o uso feito do termo deve-se ao fato de observar, cotidianamente, certas imprecisões semânticas, expressões que parecem confundir o sentido de Pedagogia, explicitando-a de maneiras diversas, a saber:

- como metodologia;

- como didática;

- somente como designação de licenciatura em Pedagogia;

- como sinônimo de entendimento único de educação;

- como estudo da educação, excetuando-se a escola, o conhecimento, os professores, as práxis;

- como área sem objeto específico.

Considerando serem imprecisões bastante recorrentes, abordá-las-ei em conjunto, como explicação, em meu entender, para o descaso a que me referi. Nesse esforço de esclarecer, estabelecerei um percurso com incursões argumentativas sobre as obras de teóricos conhecidos, com destaque para Comenius (1592-1670), Rousseau (1712-1778) e produções contemporâneas, intencionando uma inter-relação entre sentidos de Pedagogia na escola como mescla de esforços não somente do presente, mas de uma longa história de elaborações conceituais. Os argumentos apresentados embasar-se-ão em pesquisa bibliográfica que estou realizando. Os dados coletados foram organizados em acordo, inicialmente, com temas relativos à ciência da educação. Depois, estes temas foram organizados em tabelas, nas quais se procedeu à categorização, mediante a leitura dos sentidos mais evidenciados pelos autores lidos. Esses autores foram selecionados ou por, em suas obras, abordarem a Pedagogia como ciência da educação ou por descreverem entendimentos de "ciências" da educação. A seguir, apresento as sistematizações até agora produzidas organizadas em uma sequência que inclui a historicidade da Pedagogia, a discussão sobre ciências da educação, a relação da Pedagogia com a Filosofia e a Sociologia e reflexões sobre o trabalho dos pedagogos diferenciando-o do trabalho dos professores.

\section{Um pouco de história da Pedagogia}

A Pedagogia é uma ciência recente; sua história como ciência coincide com o final do século 19 e o início do século passado. Entretanto, já se 
falava em Pedagogia desde a Antiguidade Clássica. Nessa época, não havia uma teorização da Pedagogia, ou a compreensão de ser ciência da educação, mas era praticada uma ação pedagógica.

Desde a Grécia delineou-se uma dupla referência para o conceito de pedagogia. De um lado, desenvolveu-se uma reflexão estreitamente ligada à filosofia, elaborada em função da finalidade ética que guia a atividade educativa. De outro lado, o sentido empírico e prático inerente à paideia, entendida como a formação da criança para a vida, reforçou o aspecto metodológico presente já no sentido etimológico da pedagogia como meio, caminho: a condução da criança. (Saviani, 2007).

É muito divulgada a compreensão de que foram os gregos que cunharam a palavra Pedagogia, referindo-se ao escravo que acompanhava as crianças à escola.

O termo pedagogia deriva do grego e quer dizer amigo (gogo) da criança (pedo). Originalmente o termo designava o escravo que levava as crianças para a escola (scholé, que quer dizer ócio, em grego) para que o ludus magister (mestre de jogos ou brincadeiras) permitisse a educação (do latim ex, que quer dizer para fora e duccere, que quer dizer conduzir, ou seja, educação, do latim ex duccere, quer dizer conduzir para fora). Traduzindo a frase anterior: o amigo da criança (pedagogo) levava-os para o ócio (scholé = escola) para que o mestre de brincadeira (ludus magister) permitisse que as crianças conduzissem para fora (ex duccere) seu potencial. (Bello, 2008, p. 1).

Do mesmo modo, foram os gregos os primeiros a elaborar concepções pedagógicas sobre a prática educacional (Ferreira, 2001). Por concepções pedagógicas, entendo com Saviani (2006, p. 31): "em termos concisos, podemos entender a expressão 'concepções pedagógicas' como as diferentes maneiras pelas quais a educação é compreendida, teorizada e praticada". Essas concepções greco-latinas, a despeito do tempo e das modificações sociais, ainda se mantêm como fundamentos educacionais e se tornaram alicerces de diversas teorias e estudos na área, conforme Cambi (1999, p. 74): "Também na pedagogia, a Grécia operará uma série de inovações que marcarão o destino desse saber no Ocidente [...]". Para o autor, as contribuições principais seriam: a) "[...] passagem da educação (como práxis e como tradição) à pedagogia (como teoria e como construção de modelos autônomos e inovadores em relação à tradição)"; b) a Paideia, cuja centralidade era a crença de que "[...] o homem só é tal por meio do comércio íntimo com a cultura, que deve estruturá-lo como sujeito e torná-lo indivíduo-pessoa"; c) os studia humanitatis, "[...].ligados à centralidade da literatura e da história, dos saberes do homem e pelo homem, que devem ser também o eixo cultural da escola e dos próprios programas de estudo"; d) e, ainda, a divisão da escola em dois âmbitos: "desinteressada, cultural, de caráter teórico e contemplativo, por um lado; técnica, pragmática, de caráter aplicativo, por outro, realizada nas oficinas e destinada ao aprendizado". 
Especialmente a Paideia influenciou os estudos e práticas pedagógicas após os gregos. De acordo com Cordova, (1994, p. 42),

A pedagogia, a paideia cumprem o papel de formação dos indivíduos para atingir uma doxa correta, para serem capazes de julgar e escolher com maior acerto, construindo, com sua autonomia, os seus limites, segundo os interesses do mundo comum a ser construído. Essa questão dos limites está associada ao fato de que, numa democracia, o povo autônomo, embora possa fazer toda e qualquer coisa, não deve fazer toda e qualquer coisa.

Com o passar do tempo, as contribuições de diversos estudiosos e as teorias surgidas, a Pedagogia passou a designar a reflexão feita sobre a educação, uma espécie de meta-educação.

O momento seguinte que destaco é o nascimento da pedagogia moderna: trata-se da confluência de diversas proposições de diferentes autores da época que, somadas, configuram um novo modo de pensar e propor a educação. Para fins deste texto, destaque-se que, nos séculos 17 e 18, encontram-se vários trabalhos que contribuirão para se estabelecer uma tradição pedagógica, entre eles, os trabalhos de Comenius e de Rousseau, os quais abordo rapidamente.

Comenius (1592-1670), em sua Didática Magna, inaugura, para além da didática, uma série de descrições de uma pedagogia que estaria em acordo com uma concepção de ser humano, de Pedagogia e uma ação do Estado, entendido como provedor social. Develay (1998), citado por Franco (2008, p. 354), afirma que Comenius, ao instituir, no século 17, a Didática Magna, estava instituindo, na verdade, uma metodologia e não uma didática, já que perseguia o método de ensinar tudo a todos, a pansofia. Comenius (2006, p. 19) partia da crença de que todo ser humano é educável mediante a utilização de um método rigoroso: "Ninguém é tão feroz que não possa ser amansado." Nesta perspectiva, para o autor, todo ser humano é dotado de capacidade de conhecer, de utilizar seus sentidos e de desejo de conhecer o mundo onde se insere: "[...] o homem nasceu com a aptidão para a inteligência das coisas, para a boa ordem dos costumes e para o amor a DEUS sobre todas as coisas" (Comenius, 2006, p. 11).

Interessante é compreender como a obra de Comenius tratava da própria Pedagogia. Para ele, havia uma distinção entre o pedagogo e o professor. O professor é o responsável pela ensinança, porque é detentor do saber. Antes de abordar sobre o pedagogo e seus fazeres, destaco que, nas palavras de Narodowski, a abordagem acerca deste lugar-social dos professores é bastante esclarecedora, na medida em que Comenius compara o profissional ao que denomina criança-aluno:

O professor, e tão somente o professor, ocupa o lugar exclusivo daquele que sabe. Lugar rígido, estático e imovível, esse é o novo modelo que Comenius instala no que concerne ao exercício sobre o corpo infantil. Tal modelo baseia-se na diferença institucionalizada entre crianças e adultos, sendo que o adulto-professor é o ocupante do espaço do saber, enquanto que a criança-aluno é a ocupante de um espaço de quem não sabe, da ignorância. A criança-aluno é depositária futura do saber alheio. (Narodowski, 2004, p. 92). 
Nesta relação social, o papel dos professores é "[...] atuar sobre o aluno e restituir o estado natural de educabilidade" (Narodowski, 2004, p. 86), e, para tanto, o método é fundamental. Uma vez despertos para o conhecimento, seria implementado a todos os estudantes, ao mesmo tempo, o que Comenius denominou "instrução simultânea", uma modalidade de ensino que garantiria que todos estivessem aprendendo o mesmo e da mesma forma, tanto no âmbito do estabelecimento de ensino quanto no das salas de aulas (p. 69). Tal procedimento previa, portanto, um único professor atuando com todos os estudantes ao mesmo tempo: "[...] apenas um professor ensinando um grupo de alunos, num único e organizado esforço didático" (p. 92).

Nos tempos atuais, a participação do pedagogo na escola, ao lado dos professores, é fundamental, como afirma Pimenta (1988):

[...] a posição que temos assumido é a de que a escola pública necessita de um profissional denominado pedagogo, pois entendemos que o fazer pedagógico, que ultrapassa a sala de aula e a determina, configurase como essencial na busca de novas formas de organizar a escola para que esta seja efetivamente democrática. A tentativa que temos feito é a de avançar da defesa corporativista dos especialistas para a necessidade política do pedagogo, no processo de democratização da escolaridade.

Aos professores, na atualidade, caberia o trabalho de produzir a aula e, nela, o conhecimento, junto com os estudantes. Portanto, diferencia-se do pedagogo o cientista da educação, pois,

Enquanto o cientista está interessado em fazer avançar a sua área de conhecimento, em fazer progredir a ciência, o professor está mais interessado em fazer progredir o aluno. O professor vê o conhecimento como um meio para o crescimento do aluno; enquanto para o cientista o conhecimento é um fim, trata-se de descobrir novos conhecimentos na sua área de atuação. (Saviani, 1985, p. 19).

Obviamente, seria oportuno, e por que não dizer, primoroso, que os pedagogos fossem professores e que os professores fossem pedagogos, contribuindo para a ação pedagógica de produzir conhecimento, que, nas palavras de Dalbosco (2006, p. 1123) seria: "[...] se traz de fora o conteúdo que deve ser assimilado pela própria experiência da criança". De novo, a figura do pedagogo torna-se determinante, uma vez que é ele que está de posse dos conteúdos e que, por isso, deve dominar o processo pedagógico. Nesse caso, ter-se-ia um amálgama entre a produção da aula e a teorização, a produção científica sobre educação. Isto implica ampliar-se a ciência da educação, em seu sentido mais político, de modo a tornar-se o professor, cada vez mais, um "[...] intelectual público, até porque [...] a pedagogia é uma forma de política cultural, unida ao projecto de cidadania activa e democrática e, por isso, à própria natureza da mudança social" (Estevão, 2004, p. 23). Ou, segundo Giroux (2001, p. 15), a pedagogia deveria ser valorizada como "[...] elemento constitutivo de uma cultura política democrática que vincule as lutas sobre as identidades com o 
significado de lutas, mais amplas sobre as relações materiais do poder". E assim entender o trabalho dos professores como trabalho intelectual,

[...] quer dizer, portanto, desenvolver um conhecimento sobre o ensino que reconheça e questione sua natureza socialmente construída e o modo pelo qual se relaciona com a ordem social, bem como analisar as possibilidades transformadoras implícitas no contexto social das aulas e do ensino. (Giroux, 2001, p. 157).

Por tais motivos, pode-se afirmar que Comenius queria uma ação pedagógica diferenciada da escola de sua época. As escolas eram, para Comenius, demasiadamente retrógradas, segmentadas, e caberia aos pedagogos reinventá-las, tornando-as mais eficientes na ação de educar. Haveria futuro para as escolas: "As escolas podem se reformar para se tornarem melhores" (Comenius, 2006, p. 88).

Mesmo em um contexto de início da Idade Moderna, quando os autores propugnavam modelos educacionais sem escola, ou para além dela, à Pedagogia eram lançados desafios, como relata Boto (2003, p. 379):

A pedagogia propunha-se, desde então, como um campo do saber cuja meta seria o rompimento dos pilares da tradição, para firmar conceitos teóricos e procedimentos metodológicos que se apresentassem universalmente válidos e cientificamente comprovados para preparar o caminho das gerações vindouras.

Quase dois séculos depois de Comenius, Rousseau contrapor-se-á a tal perspectiva, abominando as escolas, suprimindo-as e relacionando educação e natureza, em uma época, a iluminista, na qual o Estado passa a ser, paulatinamente, responsabilizado pela educação.

São conhecidas várias críticas feitas às proposições de Rousseau: ser um teórico elitista e individualista; apresentar-se demasiadamente otimista em relação à ação da natureza; reduzir demais o papel do professor; separar estudante e sociedade. Apesar dessas críticas, pode-se afirmar que o romantismo de Rousseau, expresso, sobretudo, na novela pedagógica Emílio, completa os ideais iluministas, despertando o sentimentalismo e o valor à natureza, além do estímulo à busca, na simplicidade, da realização pessoal. Segundo Amado e Boavida (2008, p. 9), a referência feita a Rousseau, "[...] como 'pai' das Ciências da Educação, resulta de algumas coincidências e outras tantas confusões. Rousseau é, de facto, considerado como um precursor da Educação Nova". A novela pedagógica Emílio, de Rousseau, imagina seguir o crescimento e o processo educativo de um menino desde o nascimento até o casamento. Emílio, nobre e órfão, será levado para o campo e crescerá sob a orientação vigilante e atenta do preceptor. É um "rapaz comum" que vive com o preceptor-amigo, o qual lhe aplica a regra de seguir o que a natureza indica, e cresce em ritmos lentos, mas produzindo conhecimentos que lhe são úteis. Estes são aprendidos no "tempo certo", quando a sua maturidade psicológica permite uma real assimilação: assim ocorre tanto para os componentes curriculares científicos como para os conhecimentos 
da história, da religião e da moral. Nesse longo caminho, o trabalho do preceptor é o de "retardar" o mais possível esses aprendizados, de modo a evitar qualquer antecipação perigosa, e permitir que Emílio viva o mais longamente possível a própria infância, idade da alegria e da liberdade. Além de favorecer a natureza no seu lento desenvolvimento, o preceptor também orienta o menino, corrige-o a fim de evitar os maus hábitos e os desvios de comportamentos naturais. (Cambi, 1999, p. 348)

Desse modo, se pode afirmar que Rousseau entende por natureza a vida original, pura, sem influências dos convencionalismos sociais. O processo educativo consiste em desenvolver o estudante de acordo com a natureza, na evolução harmoniosa do amor próprio e do amor ao próximo, levá-lo a desenvolver-se na liberdade iluminada pela razão (Giles, 1985, p. 76-77). Em suma:

O pensamento pedagógico de Rousseau pode ser articulado segundo dois modelos, o do Emílio, em que são centrais as noções de educação negativa e de educação indireta, como também o papel particular que assume o educador, e o do Contrato, que versa sobre uma educação totalmente socializada regulada pela intervenção do Estado. E são dois modelos alternativos, ao mesmo tempo, complementares entre si. (Cambi, 1999, p. 344).

Nos séculos posteriores, Rousseau será inspirador de propostas em educação. Surgirão, no cenário educacional, outras obras igualmente importantes, como relatam Amado e Boavida (2008, p. 9):

\begin{abstract}
Ainda na viragem do século XVIII para o XIX, vamos encontrar autores importantes como Pestalozzi (1746-1827), Herbart (1776-1841), Froebel (1782-1852). Herbart, por exemplo, é por muitos considerado o pai da Pedagogia científica ou Ciência da Educação; é, pelo menos, alguém que influencia de forma extraordinária o pensamento pedagógico do século XIX e início do século XX, quer pelo pendor moralista que defende para a educação, quer pela exigência de aplicação da psicologia.
\end{abstract}

Nesse período, paralelamente ao advento de várias ciências, também surgem os primeiros usos da expressão "ciência da educação", que "tem a sua gênese no século XIX, um período fortemente marcado pela visão positivista da ciência a cujo esforço e intenção racionalizadora a problemática educativa não podia escapar" (Amado, Boavida, 2008, p. 10). Nessa perspectiva, a Pedagogia surge como uma ciência, um arcabouço de saberes a serem ensinados, não tendo autonomia, pois se constituía "[...] num ramo da Filosofia, especulando sobre a formação do cidadão, ainda que para isso recorresse a conhecimentos produzidos no âmbito da Psicologia e da Sociologia" (Amado, Boavida, 2008, p. 11). É com essa característica que se tornará um componente curricular em cursos de educação.

Nesse contexto, Durkheim defenderá a separação entre Pedagogia e as ciências da educação, afirmando que aquela era muito normativa e prescritiva, e esta seria atenta aos fenômenos educacionais cotidianos (Amado, Boavida, 2008, p. 10). Tal defesa subsidiará a influência do escolanovismo 
na Pedagogia, gerando estudos sobre o que foi denominado de Pedagogia Experimental, que Amado e Boavida (2008, p. 12) assim explicam:

A visão positivista da Educação própria do período anterior não só permanece como evolui para atitudes de maior sistematicidade, mantendo como modelo as ciências físicas. A ciência da educação afirma-se como uma psicologia aplicada e cujo objecto é, essencialmente, a realidade individual de cada criança, do educando.

Para Manacorda (1996), a Pedagogia evoluiu muito nos dois últimos séculos: vem conquistando seu lugar de ciência; deixou de considerar seu objeto apenas a educação das elites e passou a preocupar-se com a educação de todos os seres humanos, renovando seus conteúdos e procedimentos para tal afã; centrou-se na criança (Saviani, 1996, p. 9). Contribuiu, desse modo, para

[...] delinearem-se assim quadros muito diversos da pedagogia moderna. Esses quadros têm, sem dúvida, valor didático, pois ao classificá-los de modo distinto evidenciaram múltiplos aspectos das diferentes posições pedagógicas; isto pode contribuir para a compreensão de um fato histórico, a saber: que as posições pedagógicas defendidas nunca foram homogêneas, no entanto, quer pela genealogia, quer pelas suas repercussões, revelaram sempre numerosos pontos de contato. (Suchodolski, 2000, p. 13).

Talvez essa mudança caracterizadora da Pedagogia, sobretudo no século passado, revele muito mais de sua intenção em evoluir e se estabilizar como ciência do que se imagina. Ao se dedicar a refletir sobre a publicização e a necessária expansão da educação, a Pedagogia assume seu viés político, deixando de ser apenas a explicitação de referências acerca da educação para se tornar, paulatinamente, científica, ou seja, expressão de intencionalidades, teorias, práticas e ações em educação.

\section{A Pedagogia em suas relações com outras ciências}

Para quem se dedica a estudar a Pedagogia, faz-se imprescindível a leitura de outras áreas do conhecimento, como a Filosofia, a História, a Sociologia, a Psicologia, a Biologia, entre muitas outras, cujas produções contribuem para que se possa entender e aprofundar investigações sobre o fenômeno educacional, objeto da ciência da educação, a Pedagogia. Em outras palavras: a educação, um processo social "complexo e dinâmico", exige ser abordada a partir de uma percepção "multirreferencial", o que significa haver uma unidade no saber pedagógico resultante da pluralidade cultural pertinente aos diferentes campos curriculares, "[...] esto es, el objeto de la Pedagogía deja de estar repartido entre los campos, para asumirse como entidad definida y distintiva, pero susceptible de miradas y enfoques diversos en su proceso de construcción permanente" (Mendoza, 2004, p. 5). Especialmente a Filosofia contribui, já que permite compreender e analisar o conhecimento como produção humana. 
A relação entre Filosofia e Pedagogia já se encontra estabelecida, ainda que de modo meio subterrâneo, na própria história da Filosofia, bem antes do nascimento da Pedagogia como um campo específico de saber. Tal relação fora pensada, de modo geral, a partir do conceito de Filosofia como ciência defensora de um metafísico sistema, com pretensões universais, cujo objetivo era tratar do todo, englobando tudo o que estava ao seu redor. Resulta disso, em primeiro lugar, uma relação vertical entre ambas, na qual compete à Filosofia oferecer os fundamentos à Pedagogia. Esta ideia da Filosofia como fundamento da educação se encontra não só nos textos dos filósofos, como também, e sobretudo, em muitos manuais de filosofia da educação (Dalbosco, 2006, p. 1121).

Não somente se faz necessário conhecer a história da Filosofia relacionada à Pedagogia, mas entender como os conceitos filosóficos vão se elaborando e se substituindo nessa história, o que exige adentramento na obra dos grandes filósofos: "Isto é, a pedagogia traz para dentro de seu conteúdo aquela postura filosófica de determinar o que é racional e válido, baseando-se em algo (a Ideia, a Substância ou Deus) que vem de fora da própria racionalidade [...]" (Dalbosco, 2006, p. 1122). Pensando especificamente na Pedagogia, há o estudo dos problemas da área em um contexto caracteristicamente ontológico, porque "[...] trata primeiro da definição das 'essências' para somente depois tratar da 'realidade', fazendo com que não se alcance mais, em última instância, a própria historicidade da ação humana", e Dalbosco exemplifica com o conceito de Educação Infantil, quando denota supor que "[...] embora a criança não nasça sabendo, ela traz dentro de si uma essência que precisa ser desabrochada pelo trabalho do pedagogo". Porém, essa essência é estimulada a emergir a partir da ação dos pedagogos em relação à infância, evitando que se perca e não se constitua o cidadão autônomo. Por isso, para o autor, "a criança é vista desde o princípio como um pequeno adulto cujo desenvolvimento necessita de uma intervenção constante do adulto".

A Sociologia, outra dessas grandes parceiras da Pedagogia, tem sido discutida em vários momentos da História, desde seu surgimento como ciência, no século 18. Essa parceria tem início no momento em que se assume uma atitude teórica, creio, inquestionável, para os pedagogos: a educação é interação, acontece nas relações humanas. Ora o estudo do social, em suas diferentes abordagens, é objeto da Sociologia. Uma das grandes discussões relativas a essa ciência diz respeito ao método e, nesse, a implicação ou não do sociólogo com o fenômeno social que analisa. Na perspectiva da isenção, o sociólogo permanece exterior ao social, contempla-o percebendo-lhe seus aspectos autônomos radicais: uma autonomia ontológica (o grupo social analisado existe em sua funcionalidade), metodológica (exclui a dialética, analisando focadamente os eventos) e recíproca (a busca da objetividade por parte do sociólogo, olhando os fatos como se vivesse externamente a eles). Contrário a esses procedimentos, Sartre (2002, p. 64) propõe que o sociológo e seu objeto de estudo "[...] formam um par, no qual cada um deve ser interpretado pelo outro e onde a relação deve ser, por seu turno, decifrada como um 
momento da História." Isto porque o objeto de estudo do sociólogo, o social e, nele, o grupo social, não é um objeto metafísico, é "[...] uma multiplicidade de relações e de relações entre essas relações" (p. 67). Por isso, reitera o autor que considera: a relação entre o sociólogo e o objeto de estudo "[...] como uma relação de reciprocidade; o pesquisador nunca pode estar 'fora' de um grupo, a não ser na medida em que está 'em' um outro - salvo nos casos-limite em que esse exílio é o oposto de um ato real de exclusão" (p. 67).

Com isso se percebe haver necessidade de o sociólogo - no caso do fenômeno educacional, por exemplo, objeto da ciência da educação, a Pedagogia - além de estar imerso no fenômeno, de modo a compreendê-lo em sua interioridade, poder compreender a realidade do entorno.

\section{Nem todos os professores são pedagogos: os cientistas da educação e seu trabalho}

Passo a apresentar considerações sobre o trabalho específico dos cientistas da educação, os pedagogos. Estes profissionais desempenham (ou deveriam desempenhar) nos espaços educacionais, em acordo com o fato de serem os estudiosos da educação, atividades relativas ao que Marques (1996, p. 57) denomina as dimensões da Pedagogia:

a) o plano da racionalidade cognitivo-instrumental que permite uma intervenção praxeológica nos fenômenos da educação;

b) o plano hermenêutico da interpretação dos sentidos de um determinado contexto sociocultural;

c) o plano crítico do sentido radical da emancipação humana, como horizonte de possibilidades abertas à transcendência exigida pela historicidade da liberdade.

Ao apresentar as dimensões da Pedagogia, Marques (1996, p. 59) amplia a concepção desta área, como ciência da educação, entendendo-a "[...] não apenas no aspecto epistêmico de um sujeito que projeta seu mundo para realizá-lo". Vai além, busca perceber a educação hermeneuticamente, em seu contexto, um contexto "[...] sociocultural específico de sua atuação concreta e relançado para a superação de si mesmo no sentido radical da emancipação humana". Deste modo, acredita o autor, acontecerá "[...] o tratamento pedagógico dos desafios da educação na dimensão da interlocução dos saberes".

Se a Pedagogia é uma ciência "específica para tratamentos de assuntos correlatos à prática educativa e à dinâmica educacional" (Bello, 2008, p. 2), exige que os profissionais da área sejam amplamente preparados para agir relativamente ao fenômeno educacional. Isto inclui pensar que os processos educativos para a constituição dos pedagogos precisam abranger conhecimentos variados relativos às áreas afins e à práxis pedagógica nos diferentes cotidianos educacionais. O que significa dizer "práxis pedagógica"? Bom, depende do contexto: fora da escola, é todo agir pedagógico, que pode acontecer em todos os espaços 
escolares ampliados; dentro da escola, no meu entender, toda práxis é (ou deveria ser) pedagógica, posto que a escola se constitui com e a partir do pedagógico. O pedagógico

[...] está relacionado ao modo como o grupo que compõe a escola se organiza regularmente, a como entende e produz a educação. Transita entre o individual e o coletivo, de modo dialético, elaborando-se e acontecendo cotidianamente na escola. (Ferreira, 2008).

Ao mesmo tempo, a práxis pedagógica é a essência do trabalho profissional dos professores, e, nessa perspectiva, torna-se científica "[...] e, por isso, metódica, sistemática, hermeneuticamente elaborada e teoricamente sustentada"; assim organizada, pode-se dizer uma práxis pedagógica, então, uma práxis social, porque "[...] socialmente elaborada e organizada conforme intencionalidades, conhecimentos" (Ferreira, 2008).

Portanto, na escola, a práxis é (ou deveria ser) sempre pedagógica. Nos demais espaços sociais, entretanto, não o é necessariamente, embora se o fosse, quem sabe, se poderiam ter uma cidade, uma comunidade, instituições e pessoas mais educadoras. Em todo o lugar, haveria a preocupação com os sujeitos e seus aprenderes, embora se soubesse que todos, de algum modo, já conhecem algo, não são absolutamente ignorantes, porém podem e necessitam ampliar seus saberes, refletir sobre eles e, por meio da linguagem, produzir conhecimentos. Essa utopia, talvez sonho, me movimenta, quando penso que há no social demandas do pedagógico a serem atendidas por todos os sujeitos, não somente por pedagogos, posto que pedagógico transcende à Pedagogia. Entendo que a Pedagogia é a ciência da educação, cujos postulados, crenças, teorias, reflexões e indagações, mediante métodos e divulgação, necessitam orientar a educação em seus aspectos formais e não formais. Porém, pedagógico é tudo que está implicado na ação de educar, mesmo que ainda não referendado pela Pedagogia, ou seja, no âmbito do senso comum. Quando o pedagógico está no âmbito da escola, está sobretudo regulamentado, normatizado, além de incidirem sobre ele determinadas relações de poderes, próprias daquele espaço e daquele tempo, culturalmente elaborados. Por isso se pode dizer, com Peres (2007):

Em toda práxis pedagógica há normas, ações premeditadas e instituídas que fazem os sujeitos agirem de algum modo, ou seja, cria condições para que se constituam ações, subjetividades e, a partir dessas, conhecimentos. Não são normas ou ações ingênuas. Ao contrário, estão eivadas de relações de poderes manifestas nos discursos, de modo que somente podem ser analisadas em relação ao contexto em que se produziram.

Essas relações se evidenciam cotidianamente, na escola ou em qualquer espaço onde haja relações pedagógicas. Em alguns casos, são naturalizadas pelo grupo e não estão prescritas em nenhum documento. Sua repetição as naturaliza. São modos como os sujeitos intercambiam 
saberes, culturas, historicidades. Poder-se-ia afirmar que nenhuma práxis pedagógica está desvinculada de inter-relações entre os sujeitos, pois a interação social é seu suposto, o alicerce onde acontece. Assim, a própria práxis é pedagógica, porque interativa, porque põe em interação os sujeitos, e estes, ao interagirem, desde o nível inicial, já estão em interlocução de saberes (Marques, 1996). Peres (2007) ratifica essa afirmação, argumentando que toda práxis pedagógica efetiva produz, de algum modo, em relação aos sujeitos envolvidos, estudantes e professores, e essa produção revela-se nos seguintes aspectos:

a) alternarmos conceitos e imagens (sejam advindas do vivido ou do sonhado);

b) como professores nos colocarmos no lugar de eternos aprendizes e por isso de escuta constante;

c) as relações pessoais possam estar entretecidas às relações conceituais e profissionais;

d) redimensionarmos a valorização das didáticas, dos conteúdos e das teorias "ógicas" ou "óficas" como "únicos" alicerces da futura prática (no caso da formação de professores);

e) trabalharmos uma "teoria encarnada" aos componentes imaginais e simbólicos.

É assim que se reafirma a Pedagogia como ciência dialógica, cujos princípios se revisam cotidianamente nos espaços e nos tempos da escola, pedagógicos por excelência e demasiadamente humanos. Uma ciência, portanto, cujo objeto é a educação, e esta acontece na interação entre os sujeitos, tendo a linguagem como meio (Gadamer, 1988).

\section{Considerações finais}

São ouvidas, todo dia, na Universidade, queixas dos estudantes dos cursos de Pedagogia quanto ao seu lugar social diante dos demais estudantes de graduação. Alegam que estes os menosprezam, chamando-os até de "pedabobos", tendo em vista que, quando concluírem a licenciatura, serão trabalhadores em subempregos, com subsalários. Formou-se uma pseudoconcepção de Pedagogia, como uma área imprecisa, desconexa, sem objeto de estudo. Ora, tal concepção equivocada, alimentada por aqueles que não atribuem à Pedagogia o status de direito, o de ser ciência da educação, tornou-se senso comum.

De acordo com Saviani (2006, p. 1), contrariamente, trata-se da ciência que produz teoria sobre educação: "uma teoria da prática: a teoria da prática educativa" Porém, cabe alertar que "[...] se toda pedagogia é teoria da educação, nem toda teoria da educação é pedagogia. Na verdade o conceito de pedagogia se reporta a uma teoria que se estrutura a partir e em função da prática educativa" - e o autor explica: "[...] não se constituem como pedagogia aquelas teorias que analisam a educação pelo aspecto de sua relação com a sociedade não tendo como objetivo formular diretrizes que orientem a atividade educativa." 
Faz-se necessário reconstituir essa concepção, ou, com Saviani, passar do senso comum à consciência filosófica, que significa "[...] passar de uma concepção fragmentária, incoerente, desarticulada, implícita, degradada, mecânica, passiva, simplista a uma concepção unitária, coerente, articulada, explícita, original, intencional, ativa e cultivada" (Saviani, 1980, p. 5). Obviamente, esse é um trabalho de pedagogos organizados em grupos, coletivamente articulados, posto que implica rever a teoria em ação dessa ciência. E considerar o que afirma Vázquez (1977, p. 206):

A teoria em si não transforma o mundo. Pode contribuir para sua transformação, mas para isto tem que sair de si mesma, e, em primeiro lugar, tem que ser assimilada pelos que vão ocasionar, com seus atos reais, efetivos, tal transformação.

Do mesmo modo, a teoria pedagógica em si não transforma a educação; é necessária a ação dos sujeitos, pois:

Entre a teoria e a atividade prática transformadora se insere um trabalho de educação das consciências, de organização de meios materiais e planos concretos de ação: tudo isso como passagem indispensável para desenvolver ações reais e efetivas. Nesse sentido, uma teoria é prática na medida em que materializa, através de uma série de mediações, o que antes só existia idealmente, como conhecimento da realidade ou antecipação ideal de sua transformação. (Vazquez, 1977, p. 206).

Do mesmo modo, segundo Saviani (2006, p. 31), quando há uma correlação entre teoria da educação e Pedagogia, "[...] além de compreender o lugar e o papel da educação na sociedade, a teoria da educação se empenha em sistematizar, também, os métodos, processos e procedimentos". Estes procedimentos intencionam atribuir intencionalidade à ação de educar, garantindo-lhe eficácia. Poder-se-ia dizer que o objetivo final da teoria da educação é a "prática pedagógica, isto é, o modo como é organizado e realizado o ato educativo" e o da Pedagogia é a educação (Saviani, 2006 p. 31)

Ao finalizar, caberia perguntar com Mazzotti (2006, p. 546): Se para cada teoria há um objeto de estudo referente, qual o objeto de estudo da Pedagogia? A educação não seria uma "palavra-valise"? O vocábulo educação é abrangente, com certeza abrange várias possibilidades de sentidos e compreensões, o que pode ser uma "dispersão epistemológica" da ciência da educação (que o autor chama de "ciências"). Entretanto, se pensado em seu sentido, é um mesmo fenômeno, porém em acordo com os espaços sociais onde se produz. O que se entende por educação na escola pode não ser do mesmo modo na família, ou na Igreja, ou no sindicato. Mas, em sua especificidade, em todos estes espaços sociais há educação. Por isto, concordo com Franco (2008, p. 362):

Não basta à Pedagogia refletir ou teorizar sobre o ato pedagógico; não basta à Pedagogia, também, orientar ou, muito menos, prescrever ações práticas para a concretização das práticas educativas. É preciso 
que a Pedagogia produza conhecimentos na direção da superação da fragmentação dos saberes pedagógicos, docentes e científicos que foram historicamente dissociados.

Com certeza esta discussão é inicial e exige, cotidianamente, ser assumida pelos sujeitos da educação. Deste modo, poder-se-á contribuir para a recuperação, ao lado do lugar social da educação, também do reconhecimento dos pedagogos, e mais, da educação como preponderante para a tão necessária transformação social.

\section{Referências bibliográficas}

AMADO, J.; BOAVIDA, J. Ciências da educação: epistemologia, identidade e perspectivas. 2. ed. Coimbra: Ed. Coimbra, 2008.

BELLO, José Luiz de Paiva. O fim da Pedagogia. 2008. Disponível em: $<$ http://www.pedagogiaemfoco.pro.br/filos30.htm>.

BOTO, C. A civilização escolar como projeto político e pedagógico da modernidade: cultura em classes, por escrito. Cadernos Cedes, Campinas, v. 23, n. 61, p. 378-397, dez. 2003. Disponível em: $<$ http://www.cedes.unicamp.br>.

CAMBI, F. História da Pedagogia. São Paulo: Ed. Unesp, 1999.

COMENIUS, J. A. Didática magna. São Paulo: Martins Fontes, 2006.

CORDOVA, R. A. Imaginário social e educação: criação e autonomia. Em Aberto, Brasília, v. 14, n. 61, p. 24-44, jan./mar. 1994.

DALBOSCO, C. A. O cuidado como conceito articulador de uma nova relação entre Filosofia e Pedagogia. Educação \& Sociedade, Campinas, v. 27, n. 97, p. 1113-1135, set./dez. 2006.

ESTEVÃO, C. V. Sentidos de escola, profissional docente e formação. Revista Brasileira de Política e Administração da Educação, Rio de Janeiro, v. 20, n. 2, p. 11-28, jul./dez. 2004.

FERREIRA, L. S. Educação \& História. 3. ed. Ijuí: Ed. Unijui, 2001. Gestão do pedagógico: de qual pedagógico se fala? Currículo sem Fronteiras. v. 8, n. 2, p. 176-189, jul./dez. 2008.

FRANCO, Maria Amélia Santoro. Didática e pedagogia: da teoria do ensino à teoria da formação. In: ENCONTRO NACIONAL DE DIDÁTICA 
E PRÁtICA DE ENSINO (Endipe), 14., 2008, Porto Alegre. Anais do XIV Endipe. Porto Alegre: Ed. PUC-RS, 2008. p. 350-371.

GADAMER, Hans-Georg. Verdad y método: fundamentos de una hermenéutica filosófica. 3. ed. Salamanca: Sígueme, 1988.

GAUTHIER, C. et al. Por uma teoria da Pedagogia: pesquisas contemporâneas sobre o saber docente. Ijuí: Ed. Unijui, 1998.

GENOVESI, G. Pedagogía: dall'empiria verso la scienza. Bologna: Pitágoras, 1999.

GILES, T. R. História da Educação. São Paulo: EPU, 1987.

GIROUX, H. Cultura, política y práctica educativa. Barcelona: Graó, 2001.

MANACORDA, M. A. Marx e a pedagogia moderna. 2. ed. São Paulo: Cortez, 1996.

MARQUES, M. O. Projeto pedagógico: a marca da escola. Contexto \& Educação, v. 1, n. 1, p. 16-28, abr./jun. 1990.

. Educação/interlocução, aprendizagem/reconstrução de saberes. Ijuí: Ed. Unijui, 1996.

MAZZOTTI, T. Ciências da educação em questão. Educação e Pesquisa, São Paulo, v. 32, n. 3, p. 539-550, set./dez. 2006.

MENDOZA, C. La pedagogía como ciencia: notas para un debate. Investigación y Postgrado, Caracas, v. 19, n. 2, p. 1-8, jul. 2004.

NORODOWSKI, M. Comenius e a educação. 2. ed. Belo Horizonte: Autêntica, 2002.

PERES, Lúcia Maria Vaz. Uma semente viva revitalizando e reconstruindo pessoas: relações ensinantes como subjetividades em movimento. In: : ENCONTRO NACIONAL DE DIDÁTICA E PRÁTICA DE ENSINO (Endipe), 14., 2008, Porto Alegre. Anais do XIV Endipe: trajetórias e processos de ensinar e aprender: sujeitos, currículos e cultura. Porto Alegre : Ed. PUC-RS, 2008. v. 3, p. 376-388.

PIMENTA, S. G. (Coord.). O pedagogo na escola pública. São Paulo: Loyola, 1988.

PIMENTA, S. G. (Org.). Saberes pedagógicos e atividade docente. São Paulo: Cortez, 1999. 
SAVIANI. D. Prefácio à edição brasileira. In: MANACORDA, M. A. Marx e a pedagogia moderna. 2. ed. São Paulo: Cortez, 1996.

. Educação: do senso comum à consciência filosófica. São Paulo: Cortez, 1980.

. Pedagogia histórico-crítica no quadro das tendências da educação brasileira. Revista da Associação Nacional de Educação, São Paulo, n. 11, p. 15-23, 1985.

As concepções pedagógicas na História da Educação Brasileira. In: LOMBARDI, J. C.; SAVIANI, D.; NASCIMENTO, M. I. M. (Orgs.). Navegando pela história da educação brasileira. Campinas, SP: Histedbr, 2006.

. Pedagogia: o espaço da educação na universidade. Cadernos de Pesquisa, v. 37, n. 130, p. 100-134, jan./abr. 2007.

SARTRE, J. Crítica da razão dialética: precedido por Questões de método. Rio de Janeiro: DP\&A, 2002.

SOLÀ, P. El estúdio diacrónico de los fenómenos educativos y las tendencias historiográficas actuales. In: CONGRESO INTERNACIONAL "A HISTÓRIA A DEBATE", 1993, Santiago de Compostela. Actas. Santiago de Compostela: Carlos Barros Editor, 1995. t. II, p. 213-220.

SUCHODOLSKI, B. A pedagogia e as grandes correntes filosóficas: a pedagogia da essência e a pedagogia da existência. 5. ed. Lisboa: Horizonte, 2000.

VAZQUEZ, A. D. Filosofia da práxis. Rio de Janeiro: Paz e Terra, 1977.

Liliana Soares Ferreira, doutora em Educação pela Universidade Federal do Rio Grande do Sul (UFRGS), é professora-adjunta do Departamento de Administração Escolar do Centro de Educação, na Universidade Federal de Santa Maria (UFSM).

anaililferreira@yahoo.com.br

Recebido em 12 de julho de 2009.

Aprovado em 15 de dezembro de 2009. 
